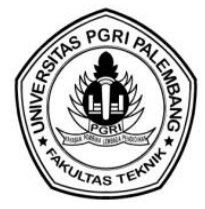

\title{
ANALISA PERENCANAAN RUNWAY, TAXIWAY, DAN APRON PADA BANDARA SULTAN MAHMUD BADARUDDIN II PALEMBANG MENGGUNAKAN METODE FAA (FEDERAL AVIATION ADMINISTRATION)
}

\author{
Herri Purwanto $^{1 *}$, Agung Sunandar ${ }^{2}$ \\ ${ }^{12}$ Prodi Teknik Sipil Fakultas Teknik Universitas PGRI Palembang \\ *Corresponding Author, Email : hei_s2@yahoo.com
}

\begin{abstract}
ABSTRAK
Bandara Sultan Mahmud Badaruddin II adalah bandara internasional yang mengalami peningkatan pesat dari tahun ke tahun hingga saat ini. Maka dari itu diperlukan pengembangan pada Bandara. Pengembangan yang diperlukan yaitu pada perkerasan runway, taxiway, dan Apron. Metode yang dipakai untuk melakukan perencanaan adalah metode FAA (Federal Aviation Administration). Perencanaan perkerasan dengan metode FAA dilakukan dengan memplot data penerbangan, jenise pesawat, beban pesawat, beban roda pesawat kedalam grafik berdasarkan jenis dari ban pesawat rencana untuk mendapatkan tebal total perkerasan.Dari hasil perhitungan didapat perkerasan runway dengan tebal surface 10,16 cm, base course 20,64 cm, dan subbase 47,24 cm, Perkerasan taxiway dengan tebal surface 7,62 cm, base course 18,59 cm, dan subbase 42,4 cm. Dan perkerasan Apron sebesar 76,48.
\end{abstract}

Kata Kunci : Perkerasan, Runway, Taxiway, Apron, FAA (Federal Aviation Administration).

\section{PENDAHULUAN}

Bandar udara adalah kawasan atau wilayah di daratan dan atau perairan dengan batasbatas tertentu yang digunakan sebagai tempat pesawat udara, disamping untuk mendarat dan lepas landas, juga sebagai tempat naik turun penumpang, bongkar muat barang, dan tempat perpindahan intra dan antarmoda transportasi yang dilengkapi dengan fasilitas keselamatan dan keamanan penerbangan, serta fasilitas pokok dan fasilitas penunjang lainnya (Djoko Warsito, 2017).

Seiring dengan tarif penerbangan di Indonesia yang semakin terjangkau bagi masyarakat, maka semakin tingginya minat masyarakat Indonesia dalam menggunakan transportasi udara. Hal ini juga yang membuat Indonesia mengalami perkembangan yang sangat pesat dalam industri penerbangan. Salah satunya yaitu Bandara Sultan Mahmud Badaruddin II Palembang, dimana intensitas penerbangan dari dan ke kota palembang mengalami peningkatan pesat dari tahun ke tahun. Juga saat ini Bandara Suktan Mahmud Badaruddin II telah dijadikan embarkasi untuk pemberangkatan ibadah haji. Maka dari itu diperlukan pengembangan pada Bandara Sultan Mahmud Badaruddin II, terutama pada Runway, Taxiway, dan Apron dimana bagian tersebut merupakan area yang paling sering bersentuhan langsung dengan pesawat saat kegiatan penerbangan dilaksanakan. Yang perlu diperhatikan dalam pengembangan Runway, Taxiway, dan Apron pada suatu 
bandara adalah pada struktur perkerasannya, karena struktur perkerasan memiliki peran untuk mendistribusikan tekanan terhadap subgrade (tanah dasar). Oleh karenanya identifikasi dan evaluasi terhadap struktur tanah dasar adalah sangat penting bagi perencanaan struktur perkerasan. Dimana perkerasan terbagi menjadi dua jenis yaitu perkerasan lentur (flexible pavement) dan perkerasan kaku (rigid pavement). Pada bagian Runway dan Taxiway menggunakan perkerasan lentur sedangkan bagian Apron menggunakan perkerasan kaku.

\section{TINJAUAN PUSTAKA}

\section{Perencanaan Struktur Perkerasan}

Perkerasan memiliki peranan yang sangat penting untuk menyebarkan beban ke tanah dasar. Semakin besar kemampuan tanah dasar untuk memikul beban, maka tebal lapisan perkerasan yang dibutuhkan semakin tebal karena keseluruhan struktur perkerasan didukung sepenuhnya oleh tanah dasar. Maka identifikasi dan evaluasi terhadap struktur tanah dasar adalah sangat penting bagi perencanaan tebal perkerasan.

Perkerasan adalah struktur yang terdiri dari beberapa lapisan dengan kekerasan dan daya dukung yang berlainan, perkerasan yang dibuat dari campuran aspal dengan agregat digelar diatas suatu permukaan material granular mutu tinggi disebut perkerasan flexible, sedangkan perkerasan yang dibuat dari slab slab beton (portland cement concrete) disebut perkerasan rigid. Perkerasan flexible terdiri dari lapisan-lapisan surface coarsre, base course, dan subbase course. Perkerasan rigid terdiri dari slab-slab beton dengan tebal $20 \mathrm{~cm}$, digelar diatas lapisan yang telah dipadatkan. Lapisan yang berdampingan dibawah lapisan beton, disebut subbase, bukan base course, sebab kualitasnya tidak perlu setinggi material yang ada dibawah lapisan surface course pada perkerasan flexible

\section{Menentukan Ketebalan Perkerasan}

Di dalam menentukan ketebalan perkerasan, terlebih dulu harus ditentukan "pesawat rencana" yaitu data pesawat yang bebannya akan menghasilkan ketebalan perkerasan yang paling besar. Di dalam rancangan lalu lintas pesawat, perkerasan harus melayani berbagai macam pesawat, yang mempunyai tipe roda pendaratan berbeda-beda dan berlainan beratnya. Pengaruh dari semua jenis model lalu lintas harus dikonversikan kedalam pesawat rencana dengan equivalent annual departure dari pesawat campuran tersebut.

Adapun rumusan konversinya adalah sebagai berikut :

$\log \mathrm{R} 1=(\log \mathrm{R} 2)\left(\frac{W 2}{W 1}\right)^{\frac{1}{2}}$

$\mathrm{R} 1=$ Equivalent Annual Departure pesawat rencana

$\mathrm{R} 2$ = Annual Departure pesawat-pesawat camouran dinyatakan dalam roda

pedaratan pesawat rencana

$\mathrm{W} 1=$ Beban roda dari pesawat rencana

$\mathrm{W} 2$ = Beban roda dari pesawat yang ditanyakan

Untuk pesawat berbadan lebar, diasumsikan mempunyai berat 300.000 lbs dengan roda pendaratan dual tandem. Untuk Tipe roda pendaratan menggunakan faktor konversinya seperti tabel berikut : 
Tabel 1. Faktor Konversi tipe roda pendaratan tiap pesawat

\begin{tabular}{|llc|}
\hline Konvensi dari & \multicolumn{1}{c}{ e } & Faktor pengali \\
\hline Single Wheel & Dual Wheel & 0,8 \\
Single Wheel & Dual Tandem & 0,5 \\
Dual Wheel & Dual Tandem & 0,6 \\
Double Dual Tandem & Dual Tandem & 1,00 \\
Dual Tandem & Single Wheel & 2,00 \\
Dual Tandem & Dual Wheel & 1,70 \\
Dual Wheel & Single Wheel & 1,30 \\
Double Dual Tandem & Dual Wheel & 1,70 \\
\hline
\end{tabular}

Sumber : Heru Basuki, 1986

Tipe roda pendaratan menentukan bagaimana berat pesawat yang nantinya akan membagi bebannya kepada roda-roda dan diteruskan ke perkerasan. Dan ini akan menentukan berapa tebal perkerasan yang bisa/ mampu melayani berat seluruh pesawat tersebut. Untuk Annual departure lebih dari 25.000, tebal total perkerasannya harus ditambah dengan mengikuti tabel berikut:

Tabel 2. Tebal Perkerasan bagi tingkat departure $>25.000$

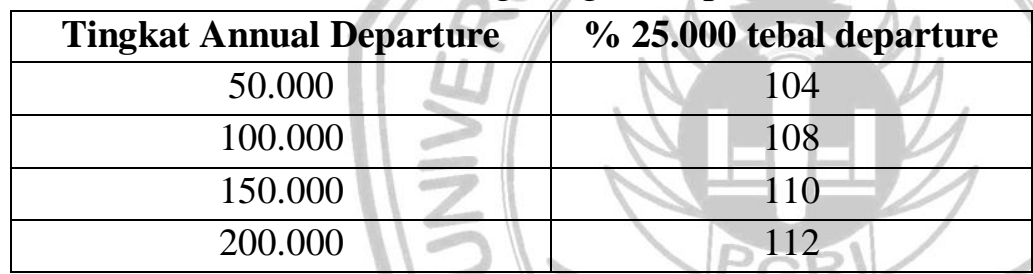

Sumber : Heru Basuki, 1986

Untuk mendapatkan lapisan perkerasan yang lebih baik, material Subbase dan base course perlu diadakan stabilisasi, dimana keuntungannya terutama pada perkerasan flexible. Tebal lapisan subbase yang telah distabikisasi dapat dilihat pada tabel dibawah ini :

Tabel 3. Faktor Equivalent untuk subbase yang distabilisasi

\begin{tabular}{|l|c|}
\hline \multicolumn{1}{|c|}{ Bahan } & Faktkor Equivalent \\
\hline P-401, Bituminous Surface Course & $1,7-2,3$ \\
\hline P-201, Bituminous Base Course & $1,7-2,3$ \\
\hline P-215, Cold Laid Bituminous Base Course & $1,5-1,7$ \\
\hline P-216, Mixed In Place Base Course & $1,5-1,7$ \\
\hline P-304, Cement Treated Base Course & $1,6-2,3$ \\
\hline P-301, Soil Cement Base Course & $1,5-2,0$ \\
\hline P-209, Crushed Agregate Base Course & $1,4-2,0$ \\
\hline P-154, Subbase Course & 1,0 \\
\hline
\end{tabular}

Sumber : Heru Basuki, 1986 
Demikian pula dengan Base course yang telah distabilisasi terlihat pada tabel dibawah ini:

Tabel 4. Faktor Equivalent untuk base yang distabilisasi

\begin{tabular}{|l|c|}
\hline \multicolumn{1}{|c|}{ Bahan } & Faktkor Equivalent \\
\hline P-401, Bituminous Surface Course & $1,2-1,6$ \\
\hline P-201, Bituminous Base Course & $1,2-1,6$ \\
\hline P-215, Cold Laid Bituminous Base Course & $1,0-1,2$ \\
\hline P-216, Mixed In Place Base Course & $1,0-1,2$ \\
\hline P-304, Cement Treated Base Course & $1,2-1,6$ \\
\hline P-301, Soil Cement Base Course & Non Aplicable \\
\hline P-209, Crushed Agregate Base Course & 1,0 \\
\hline P-154, Subbase Course & Non Aplicable \\
\hline
\end{tabular}

Sumber : Heru Basuki, 1986

\section{HASIL DAN PEMBAHASAN}

\section{Menghitung Perkerasan dengan metode $F A A$}

Jenis perkerasan landasan pacu (runway) di Bandara Sultan Mahmud Badarudin II adalah perkerasan lentur. Sehingga langkah perhitungan perkerasan runway dengan metode FAA adalah sebagai berikut:

1. Menentukan jenis dan karakteristik masing-masing pesawat.

Dalam penentuan jenis pesawat yang dilayani, dilakukan dengan melihat jenis pesawat yang beroperasi di Bandara SMB II berdasarkan Data Angkutan Udara (DAU) pada tahun 2017. Pemilihan pergerakan pesawat ini dilakukan pada operasi penerbangan berjadwal. Adapun Jenis dan karakteristik pesawat yang beroperasi dapat dilihat pada tabel berikut :.

Tabel 5. Jenis pesawat dan karakteristik

\begin{tabular}{|c|c|c|c|c|c|c|c|c|}
\hline \multirow[b]{2}{*}{ No } & \multirow[b]{2}{*}{$\begin{array}{c}\text { Aeroplane } \\
\text { Types }\end{array}$} & \multirow[b]{2}{*}{$\begin{array}{c}\text { REF } \\
\text { CODE }\end{array}$} & \multicolumn{6}{|c|}{ Characteristic } \\
\hline & & & $\begin{array}{c}\text { ARFL } \\
\text { (m) }\end{array}$ & $\begin{array}{l}\text { Wings } \\
\text { (m) }\end{array}$ & $\begin{array}{c}\text { OMG } \\
\text { WS } \\
(\mathrm{m})\end{array}$ & $\begin{array}{c}\text { Length } \\
\text { (m) }\end{array}$ & $\begin{array}{c}\text { MTOW } \\
\text { (kg) }\end{array}$ & $\begin{array}{l}\text { MTOW } \\
\text { (lbs) }\end{array}$ \\
\hline 1 & A $320-200$ & $4 \mathrm{C}$ & 2480 & 33,9 & 8,7 & 37,6 & 77.000 & $169.755,94$ \\
\hline 2 & LEARJET 35 & $3 \mathrm{~A}$ & 1458 & 12,0 & 2,5 & 15,0 & 8.000 & $17.639,98$ \\
\hline 3 & B 737-900 ER & $4 \mathrm{C}$ & 2240 & 34,3 & 7,0 & 7 & 79.000 & 65,2 \\
\hline 4 & B $737-800$ & $4 \mathrm{C}$ & 2090 & 34,3 & 7,0 & 36,5 & 80.000 & $176.369,8$ \\
\hline 5 & B $737-500$ & $4 \mathrm{C}$ & 2470 & 28,9 & 6,4 & 31,0 & 59.000 & $130.072,7$ \\
\hline 6 & B 737300 & $4 \mathrm{C}$ & 2749 & 28,9 & 6,4 & 30,5 & 64.000 & $141.095,8$ \\
\hline 7 & CRJ 1000 & $3 \mathrm{~B}$ & 1720 & 21,2 & 4,0 & 39,1 & 42.000 & $92.594,15$ \\
\hline 8 & ATR 72-500 & $3 \mathrm{C}$ & 1355 & 27,0 & 4,1 & 27,2 & 23.000 & $50.706,32$ \\
\hline
\end{tabular}

Sumber : Angkasa Pura II 
2. Menentukan rata-rata pertumbuhan pesawat dan proyeksi Annual departure.

Menentukan rata - rata pertumbuhan pesawat dilakukan dengan menghitung jumlah pergerakan pesawat selama tahun 2017 untuk penerbangan berjadwal. Rangkuman pergerakan pesawat baik penerbangan domestik maupun internasional dapat dilihat pada tabel berikut :

Tabel 6. Pergerakan pesawat tahun 2017

\begin{tabular}{|c|c|c|}
\hline No & Jenis Pesawat & Pergerakan Pesawat \\
\hline 1 & A 320 200 & 10084 \\
\hline 2 & LEARJET 35 & 560 \\
\hline 3 & B737 - 900 ER & 4482 \\
\hline 4 & B737 - 800 & 7843 \\
\hline 5 & B737 - 500 & 1680 \\
\hline 6 & B737-300 & 560 \\
\hline 7 & CRJ 1000 & 1401 \\
\hline 8 & ATR 72-500 & 840 \\
\hline
\end{tabular}

Sumber : Angkasa Pura II

3. Menetukan angka pertumbuhan

Penentuan angka pertumbuhan (i) pergerakan pesawat dimulai dari tahun 2013-2017. Rata-rata angka pertumbuhan Bandara SMB II (2013-2017) adalah 23,3\%. Angka ini yang selanjutnya digunakan untuk proyeksi pergerakan pesawat tahunan seperti yang diberikan pada tabel :

Tabel 7. Proyeksi pergerakan pesawat tahunan

\begin{tabular}{|c|c|c|c|}
\hline No & Jenis Pesawat & Pergerakan Pesawat & Rn \\
\hline 1 & A 320 200 & 10084 & 633483 \\
\hline 2 & LEARJET 35 & 560 & 35179 \\
\hline 3 & B737 - 900 ER & 4482 & 281562 \\
\hline 4 & B737 - 800 & 7843 & 492702 \\
\hline 5 & B737 - 500 & 1680 & 105538 \\
\hline 6 & B737-300 & 560 & 35179 \\
\hline 7 & CRJ 1000 & 1401 & 88011 \\
\hline 8 & ATR 72-500 & 840 & 52769 \\
\hline
\end{tabular}

Sumber : Angkasa Pura II

Adapun persamaan yang digunakan untuk menentukan pergerakan pesawat tahunan yaitu .

$$
\operatorname{Rn}=\operatorname{Ro}(1+i)^{n}
$$

4. Penentuan nilai CBR

Berdasarkan data lapangan dari hasil wawancara dengan pihak Angkasa Pura, data nilai CBR adalah sebagai berikut :

a. Nilai CBR Subgrade : $5 \%$

b. Nilai CBR Subbase : $20 \%$ 
5. Menentukan masing-masing tipe roda pendaratan pesawat.

Tipe roda pendaratan utama sangatlah menentukan dalam perhitungan tebal perkerasan karena penyaluran beban pesawat melalui diberikan melalui roda ke perkerasan. Masing-masing roda pendaratan pesawat campuran akan dikonversi ke roda pendaratan pesawat rencana. Pesawat rencana Boeing 737 - 800 memiliki roda pendaratan dengan tipe dual wheel.

6. Menentukan Annual Departure (R2)

R2 merupakan jumlah keberangkatan tahunan (annual departure) pesawat campuran dimana diperoleh dengan cara mengalikan proyeksi pergerakan pesawat tahunan dengan faktor konversi roda pendaratan. Dimana R2 adalah Pergerakan pesawat tahunan dikali faktor konversi roda pendaratan. Hasil perhitungan pada persamaan tersebut disajikan dalam bentuk table berikut :

Tabel 8. Annual departure pesawat campuran

\begin{tabular}{|c|c|c|c|c|}
\hline No & Jenis Pesawat & $\begin{array}{c}\text { Pergerakan } \\
\text { pesawat tahunan }\end{array}$ & $\begin{array}{c}\text { Faktor } \\
\text { konversi roda } \\
\text { pendaratan }\end{array}$ & $\begin{array}{c}\text { Annual } \\
\text { Departure } \\
\text { (R2) }\end{array}$ \\
\hline 1 & A 320 200 & 10084 & 1 & 10084 \\
\hline 2 & LEARJET 35 & 560 & 0,8 & 448 \\
\hline 3 & B737 - 900 ER & 4482 & 1 & 4482 \\
\hline 4 & B737-800 & 7843 & 1 & 7843 \\
\hline 5 & B737 - 500 & 1680 & 1 & 1680 \\
\hline 6 & B737-300 & 560 & 1 & 560 \\
\hline 7 & CRJ 1000 & 1401 & 1 & 1401 \\
\hline 8 & ATR 72-500 & 840 & 1 & 840 \\
\hline
\end{tabular}

7. Menghitung beban roda pesawat campuran (W2).

W2 merupakan beban roda pesawat campuran dimana dihitung dengan menggunakan persamaan

$$
\mathrm{W} 2=0,95 \times \mathrm{MTOW} \times 1 / \mathrm{M} \times 1 / \mathrm{N}
$$

Persamaan tersebut disajikan dalam bentuk tabel berikut :

Tabel 9. Beban roda pesawat campuran

\begin{tabular}{|l|c|c|c|c|c|}
\hline \multirow{2}{*}{ No } & \multirow{2}{*}{$\begin{array}{c}\text { Aeroplane } \\
\text { Types }\end{array}$} & \multirow{2}{*}{$\begin{array}{c}\text { MTOW } \\
(\mathbf{l b s})\end{array}$} & \multicolumn{2}{|c|}{$\begin{array}{c}\text { Roda } \\
\text { Pendaratan }\end{array}$} & \multirow{2}{*}{ W2 (lbs) } \\
\cline { 4 - 5 } & & & $\mathbf{M}$ & $\mathbf{M}$ & \\
\hline 1 & A 320 - 200 & $169.755,94$ & 2 & 2 & $40.317,03$ \\
\hline 2 & LEARJET 35 & $17.639,98$ & 2 & 2 & $4.189,5$ \\
\hline 3 & B 737 - 900 ER & $174.165,2$ & 2 & 2 & $41.364,2$ \\
\hline 4 & B 737 - 800 & $176.369,8$ & 2 & 2 & $41.887,8$ \\
\hline 5 & B 737 - 500 & $130.072,7$ & 2 & 2 & $30.892,3$ \\
\hline 6 & B 737 300 & $141.095,8$ & 2 & 2 & $33.510,25$ \\
\hline 7 & CRJ 1000 & $92.594,15$ & 2 & 2 & $21.991,1$ \\
\hline 8 & ATR 72-500 & $50.706,32$ & 2 & 2 & $12.042,75$ \\
\hline
\end{tabular}


8. Menghitung beban roda pesawat kritis (W1).

W1 merupakan beban roda pesawat kritis dimana bebannya diambil dari beban roda pesawat rencana yaitu pesawat B 737 - 800 dengan beban roda 41.887,8 lbs.

9. Menghitung R1

R1 merupakan Equivalent Annual Departure (EAD) atau keberangkatan tahunan ekivalen oleh pesawat rencana dimana dihitung dengan menggunakan persamaan berikut.

$$
\log \mathrm{R} 1=\log \mathrm{R} 2\left(\frac{W 2}{W 1}\right)^{0,5}
$$

Tabel 10. Tebal perhitungan Equivalent Annual Departure

\begin{tabular}{|c|c|c|c|c|c|c|}
\hline No & Jenis Pesawat & $\begin{array}{c}\text { Annual } \\
\text { Departure } \\
(\mathbf{R 2})\end{array}$ & Log R2 & $\left(\frac{W 2}{W 1}\right)^{\mathbf{0 , 5}}$ & Log R1 & $\begin{array}{c}\text { Equivalent } \\
\text { Annual } \\
\text { Departure } \\
(\mathbf{R} 1)\end{array}$ \\
\hline 1 & A 320 200 & 10084 & 4,0036 & 0,98 & 3,92 & 8317,64 \\
\hline 2 & LEARJET 35 & 448 & 2,65 & 0,32 & 0,85 & 7,08 \\
\hline 3 & B737 - 900 ER & 4482 & 3,65 & 0,99 & 3,61 & 4073,8 \\
\hline 4 & B737 - 800 & 7843 & 3,89 & 1 & 3,89 & 7762,5 \\
\hline 5 & B737 - 500 & 1680 & 3,225 & 0,86 & 2,77 & 588,84 \\
\hline 6 & B737-300 & 560 & 2,75 & 0,89 & 2,45 & 281,84 \\
\hline 7 & CRJ 1000 & 1401 & 3,15 & 0,72 & 2,27 & 186,21 \\
\hline 8 & ATR 72-500 & 840 & 2,92 & 0,54 & 1,58 & 38,02 \\
\hline & & \multicolumn{2}{r|}{ Total } & & 21255,93 \\
\hline
\end{tabular}

Dari persamaan tersebut kemudian ditentukan EAD dengan masing-masing pesawat rencana. Berdasarkan perhitungan yang telah dilakukan didapat pesawat B737-800 sebagai pesawat rencana dengan $21.255,93$ pergerakan.

10. Menghitung tebal perkerasan Runway

Dalam penentuan tebal perkerasan metode FAA, dilakukan menggunakan grafik sesuai dengan tipe roda pendaratan pesawat rencana yaitu dual wheel gear. Tebal perkerasan total dihitung dengan memplotkan data CBR subgrade, MTOW (Maximum Take Off Weight) pesawat rencana, dan nilai Equivalent AnnualDeparture ke grafik sesuai dengan pesawat rencana. 


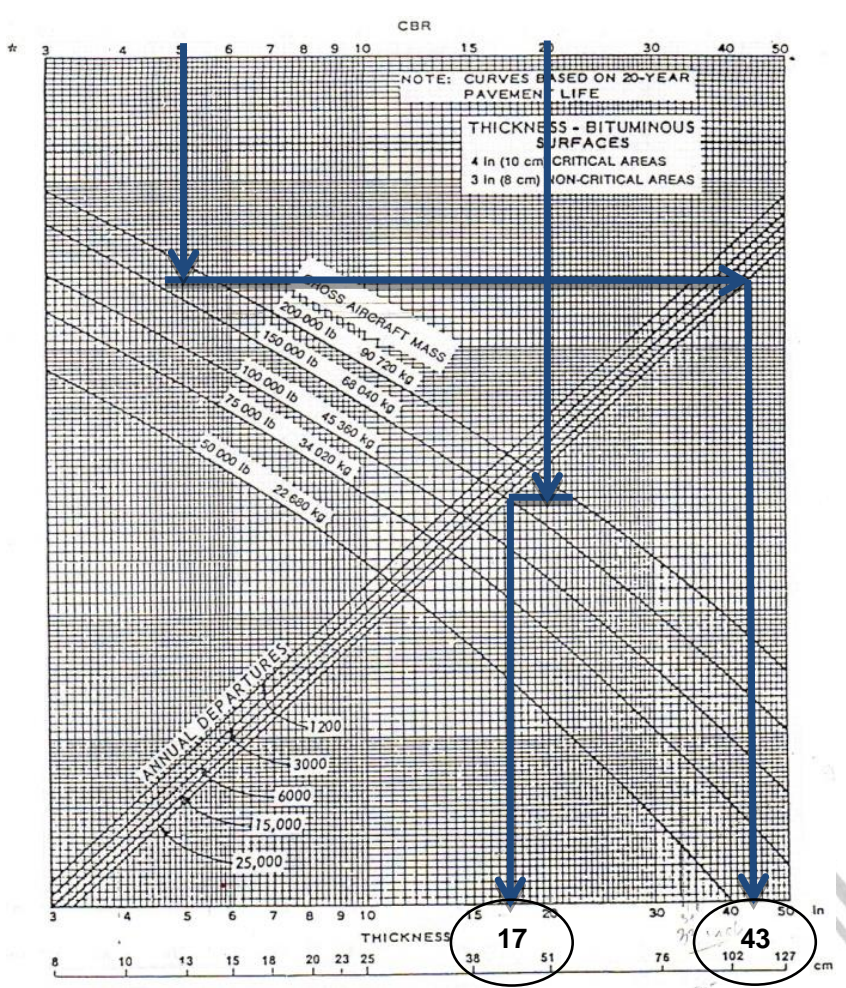

Gambar 1. Grafik perkerasan lentur pada daerah kritis dengan tipe dual wheel gear

Maka didapat hasil perkerasan seperti terlihat di tabel dibawah ini

Tabel 11. Tebal perkerasan tiap landasan

\begin{tabular}{|c|c|c|c|c|c|c|}
\hline \multirow{2}{*}{ Lapisan } & \multicolumn{2}{|c|}{ Kritis (T) } & \multicolumn{2}{c|}{ Non Kritis (0,9 T) } & \multicolumn{2}{c|}{ Pinggir (0,7 T) } \\
\cline { 2 - 8 } & Inch & $\mathbf{c m}$ & Inch & $\mathbf{c m}$ & Inch & $\mathbf{c m}$ \\
\hline Surface & 4 & 10 & 3 & 8 & 2,8 & 7 \\
\hline Base Course & 13 & 33 & 11,7 & 30 & 9,1 & 23 \\
\hline Subbase Course & 26 & 66 & 23,4 & 59 & 18,2 & 46 \\
\hline
\end{tabular}

Tabel 12. Tebal perkerasan runway tiap lapisan setelah stabilisasi

\begin{tabular}{|c|c|c|c|c|c|}
\hline \multirow{3}{*}{ Lapisan perkerasan } & \multicolumn{4}{|c|}{ Perbandingan } & \multirow{3}{*}{$\begin{array}{c}\text { Deviasi } \\
(\%)\end{array}$} \\
\hline & \multicolumn{2}{|c|}{ Eksisting } & \multicolumn{2}{|c|}{ Perhitungan } & \\
\hline & Inci & $\mathbf{C m}$ & inci & $\mathbf{C m}$ & \\
\hline Lapisan permukaan (Surface) & 4 & 10,16 & 4 & 10,16 & 0 \\
\hline Lapis Pondasi Atas (Base) & 6,7 & 17,00 & 8,125 & 20,64 & 15 \\
\hline Lapis Pondasi Bawah (Subbase) & 16,5 & 42,00 & 18,6 & 47,24 & 15 \\
\hline Total & 27,1 & 69,16 & 30,725 & 78,04 & 30 \\
\hline
\end{tabular}


Tabel 13. Tebal perkerasan taxiway

\begin{tabular}{|c|c|c|}
\hline \multirow{2}{*}{ Jenis Perkerasan } & \multicolumn{2}{|c|}{ Hasil Perhitungan } \\
\cline { 2 - 3 } & In & $\mathbf{c m}$ \\
\hline Overlay & - & - \\
\hline Surface Course & 3 & 7,62 \\
\hline Base Course & 7,32 & 18,59 \\
\hline Subbase Course & 16,7 & 42,4 \\
\hline Total & 30,02 & 76,23 \\
\hline
\end{tabular}

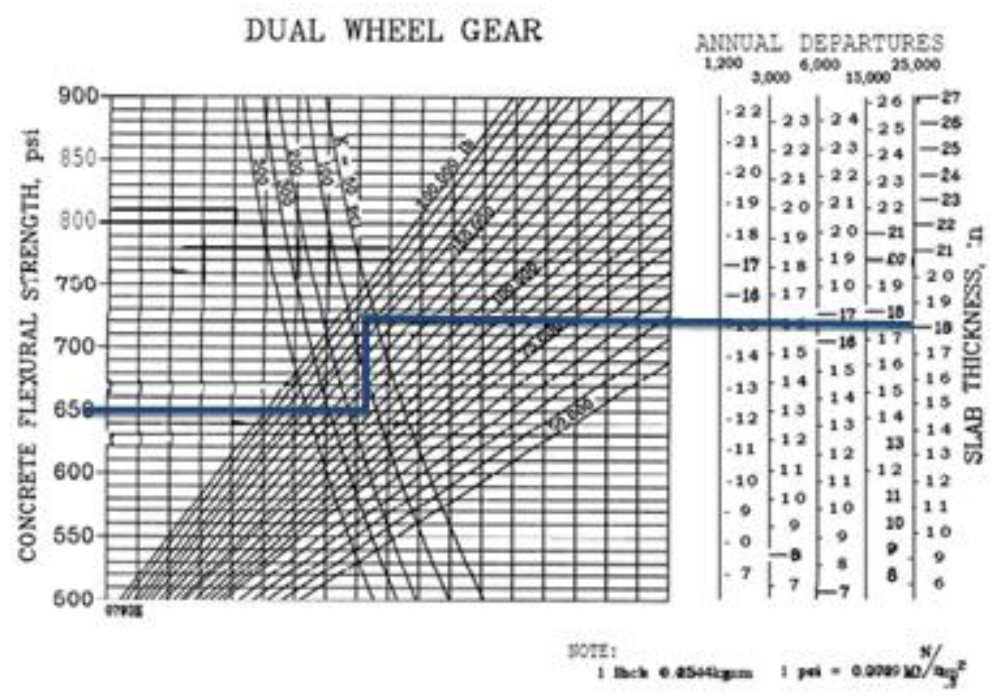

Gambar 2. Grafik perkerasan kaku untuk mendapatkan tebal slab beton

Tabel 14. Tebal perkerasan apron

\begin{tabular}{|c|c|c|}
\hline \multirow{2}{*}{ Jenis Perkerasan } & \multicolumn{2}{|c|}{ Hasil Perhitungan } \\
\cline { 2 - 3 } & In & cm \\
\hline Surface Course & 18 & 46 \\
\hline Base Course & 6 & 15,24 \\
\hline Subbase Course & 6 & 15,24 \\
\hline Total & 30 & 76,48 \\
\hline
\end{tabular}

\section{KESIMPULAN}

Berdasarkan analisa dan perhitungan dengan menggunakan metode FAA, disimpulkan sebagai berikut:

a. Tebal perkerasan runway sebesar $78,04 \mathrm{~cm}$, yang terdiri dari 10,16 cm surface course, 20,64 cm base course, dan 47,24 cm subbase course.

b. Tebal perkerasan taxiway sebesar 76,23 cm, yang tetrdiri dari 7,62 cm surface course, $18,59 \mathrm{~cm}$ base course, dan 42,4 cm subbase course.

c. Tebal perkerasan Apron sebesar 76,48. Karena perkerasan Apron menggunakan perencanaan perkerasan rigid tanpa tulangan lapisan yang dihasilkan hanya tebal slab beton yaitu $46 \mathrm{~cm}$, Untuk base course tebal 15,24 cm dan subbase course tebal 15,24 cm diambil dari tebal eksisting Apron. 


\section{DAFTAR PUSTAKA}

Anton Manontong Nababan, Eduardi Prahara, ST,. MT , Desain Tebal Perkerasan Dan Panjang Runway Menggunakan Metode FAA; Studi Kasus Bandara Internasional Kuala Namu Sumatera Utara

Basuki, Heru. 1986. Merancang dan Merencana LapanganTerbang. Penerbit Alumni 1986 Bandung

Brian Charless, Sri Djuniati, Ari Sandiyavitri, 2016, Analisis Perencanaan Struktur Perkerasan Runway, Taxiway, Dan Apron Bandara Sultan Syarif Kasim II Menggunakan Metode FAA

Buku Panduan Kuliah, Lapangan Terbang, Fakultas Tenik Universitas 17 Agustus 1945, Semarang

Hazanawati, Wardhani Sartono, 2008, Kajian Pengembangan Sisi Udara Bandar Udara Japura Kabupaten Indragiri Hulu

Horonjeff, Robert. McKelvey, X, Francis., 1988, "Perencanaan dan Perancangan Bandar Udara Edisi Ketiga Jilid I',

Sartono, Wardhani, Dewanti, Rahman, Taqia, 2016 Bandar Udara

Sheellfia J. Permana, Ir. Hera Widyastuti, MT.Ph.D, 2013, Studi Perencanaan Pengembangan Landas Pacu (Runway) Dan Landas Hubung (Taxiway) Bandara Abdulrachman Saleh Malang

Warsito, Djoko, 2017. "Manajemen Bandar Udara: Landasan Pacu, Taxiway dan Appron”. Erlanggga 